\title{
Optimal Sizing of Solar/Wind Hybrid Off-Grid Microgrids Using an Enhanced Genetic Algorithm
}

\author{
Abdrahamane Traoré, Hatem Elgothamy, Mohamed A. Zohdy \\ Department of Electrical and Computer Engineering, Oakland University, Rochester, MI, USA \\ Email: atraore@oakland.edu
}

How to cite this paper: Traoré, A., Elgothamy, H. and Zohdy, M.A. (2018) Optimal Sizing of Solar/Wind Hybrid Off-Grid Microgrids Using an Enhanced Genetic Algorithm. Journal of Power and Energy Engineering, 6, 64-77.

https://doi.org/10.4236/jpee.2018.65004

Received: February 13, 2018

Accepted: May 28, 2018

Published: May 31, 2018

Copyright $\odot 2018$ by authors and Scientific Research Publishing Inc. This work is licensed under the Creative Commons Attribution International License (CC BY 4.0).

http://creativecommons.org/licenses/by/4.0/

\begin{abstract}
This paper presents a method for optimal sizing of an off-grid hybrid microgrid (MG) system in order to achieve a certain load demand. The hybrid MG is made of a solar photovoltaic (PV) system, wind turbine (TW) and energy storage system (ESS). The reliability of the MG system is modeled based on the loss of power supply probability (SPSP). For optimization, an enhanced Genetic Algorithm (GA) is used to minimize the total cost of the system over a 20-year period, while satisfying some reliability and operation constraints. A case study addressing optimal sizing of an off-grid hybrid microgrid in Nigeria is discussed. The result is compared with results obtained from the Brute Force and standard GA methods.
\end{abstract}

\section{Keywords}

Optimization, Off-Grid Microgrid, Renewable Energy, Energy Storage Systems (ESS), Solar Photovoltaic (PV), Wind, Battery, Hybrid, Genetic Algorithm (GA)

\section{Introduction}

Providing access to clean, reliable and affordable energy by adopting microgrid (MG) power systems is important for countries looking to achieve their sustainable development goals as the extension of the grid is time and capital expensive. These MGs are small electrical power systems that connect several electricity users to some distributed power generators and energy storage systems, which are mainly interconnected by power converters [1] and can be made of renewable energy sources or hybridized with fossil fuel generators [2]. Hybrid PV/Diesel MG power systems are used for off-grid electrification applications, and they are good for applications in hot climates [3]. However, due to the $\mathrm{CO}_{2}$ emission, 
rising price and delivery cost of diesel fuel, renewable energy sources are becoming more and more popular in MG development, especially in remote areas. Both solar and wind power sources are intermittent as they depend on weather and climate changes; however, hybridizing the two sources can overcome this drawback [4]. Furthermore, using a hybrid ESS in an MG system can increase the system stability [5]. The PV is used as the main power supply in the system. The WT is used as complementary power supply to support the load when the PV production is low (e.g. cloudy day) or not available (night times). Additionally, the ESS is used as a back-up power to support the load when the power generated by the PV and WT cannot handle the load demand. However, improper sizing of the system components may result in higher MG cost and low reliability. For example, an oversized PV array may increase the MG investment cost and decrease its stability due to the unpredictable nature of solar power generation [6] [7]. Similarly, too much ESS capacity increases the cost and not enough ESS capacity may result in low system reliability. Consequently, many optimization problems are based mainly on either cost reduction or required reliability of the MG power system [4] [8] [9] [10] [11].

Previous studies have investigated various methods of optimally sizing in different scenarios of hybrid MG applications. [4] presented a simple sizing algorithm to obtain the number of PV and WT units along with the storage capacity for a stand-alone hybrid MG. The work in [12] presented a simple method to optimize the size of PV, WT and battery using an iterative method driven by the loss of power supply probability (LPSP) to minimize the 20-year total cost including capital, operation and maintenance cost of the MG. Other research studies focused on the operation optimization of MGs [13] [14] [15] [16] [17]. In [14] a method was presented, which used an energy management strategy based on a fuzzy expert system for optimal MG ESS sizing. [16] proposed a genetic algorithm-based optimal sizing method using an operational strategy and joint-optimization for off-grid MGs.

This paper aims to find the optimal size of PV array, WT and ESS for an off-grid MG by using an enhanced GA, proposed by [18], to minimize the total cost of the MG (which includes the capital and operating costs), while satisfying the load demand at all times with a desired reliability. Figure 1 shows the architecture of a typical hybrid PV/WT/ESS off-grid MG. In the figure is a DC-coupled MG in which the PV panel and the ESS are linked via a DC/DC charge controller, creating a DC bus that carries the power from the WT via a rectifier and power the household load using an inverter. The DC-coupled microgrid uses less power conversions (resulting in a small efficiency gain) compared to an AC-coupled MG [5].

The reliability of the MG system is modeled based on the loss of power supply probability (LPSP). For optimization, an enhanced Genetic Algorithm (GA) is used to minimize the total cost of the system over a 20 -year period, while satisfying some reliability and operation constraints. A case study addressing optimal sizing of an off-grid hybrid MG in Nigeria is discussed. 


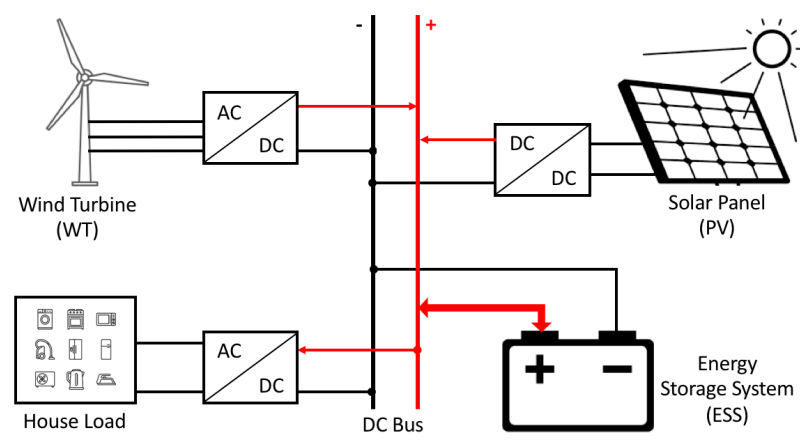

Figure 1. Architecture of hybrid PV/Wind/Battery off-grid microgrid with power converters.

\section{Mathematical Modeling of Hybrid Off-Grid Microgrid System}

\subsection{PV Model}

As the main power supply in this off-grid solar hybrid MG system, the output power of a PV module is estimated from (1) based on the solar irradiation at time $t$, and the efficiency of the PV module is given by (2).

$$
\begin{gathered}
P_{P V}(t)=\eta_{P V} \cdot A_{P V} \cdot G(t) \\
\eta_{P V}=\eta_{S T C} \cdot \eta_{M P P T}\left[1-\alpha\left(T_{C}-T_{S T C}\right)\right]
\end{gathered}
$$

where $A_{P V}$ is the area of a PV module in $\left(\mathrm{m}^{2}\right), G(t)$ is the hourly total solar irradiance in $\left(\mathrm{W} / \mathrm{m}^{2}\right), \eta_{P V}$ is the efficiency of the PV array, $\eta_{S T C}$ is reference efficiency of the PV cell at standard temperature condition (STC), $\eta_{M P P T}$ is the efficiency of the maximum peak power tracker, $T_{C}$ is the temperature of the PV cell in $\left({ }^{\circ} \mathrm{C}\right), T_{S T C}$ is the reference temperature of the PV cell at STC $\left(25^{\circ} \mathrm{C}\right)$, and $\alpha$ is the temperature coefficient of the $\mathrm{PV}$ cell (typically $0.4 \% /{ }^{\circ} \mathrm{C}-0.6 \% /{ }^{\circ} \mathrm{C}$ for silicon cells). The temperature coefficient is given by the $\mathrm{PV}$ cell manufacturer and can be obtained from the PV panel datasheet.

The cell temperature can be obtained from Equation (3).

$$
T_{C}=T_{a}+\left[\frac{N O C T-20}{800}\right] \cdot G(t)
$$

where $T_{a}$ is the ambient temperature in $\left({ }^{\circ} \mathrm{C}\right)$ and $N O C T$ is the nominal operating cell temperature $\left(45^{\circ} \mathrm{C}-47^{\circ} \mathrm{C}\right)$.

\subsection{WT Model}

The output power from a WT at time $t$ depends on the wind speed and can be obtained from (4) [19].

$$
P_{W T}(t)=\left\{\begin{array}{lc}
0 & V(t)<V_{c i} \\
a \cdot V^{3}(t)-b \cdot P_{W T}^{r} & V_{c i} \leq V(t)<V_{r} \\
P_{W T}^{r} & V_{r} \leq V(t)<V_{c o} \\
0 & V(t) \geq V_{c o}
\end{array}\right.
$$


where $a=\frac{P_{W T}^{r}}{\left(V_{r}^{3}-V_{c i}^{3}\right)} ; b=\frac{V_{c i}^{3}}{\left(V_{r}^{3}-V_{c i}^{3}\right)} ; V(t)$ is the wind speed at time $t$ in $(\mathrm{m} / \mathrm{s}) ; P_{W T}^{r}$ is the rated power of the WT in $(\mathrm{W}) ; V_{r}$ is the rated speed in $(\mathrm{m} / \mathrm{s}) ; V_{c i}$ is the cut-in speed in $(\mathrm{m} / \mathrm{s})$ and $V_{c o}$ is the cut-out speed of the WT in $(\mathrm{m} / \mathrm{s})$.

\subsection{ESS Model}

Depending on its state of charge (SOC), the ESS can supply the load when there is lack of electricity (discharge) and store surplus power when the generated power exceeds the load demand (charge). The discharging and charging energies of the ESS at time $t$ can be obtained from (5) and (6), respectively [20].

$$
\begin{gathered}
E_{E S S}^{d}(t)=E_{E S S}(t-1)-\left[E_{\text {Load }}(t)-E_{P V}(t)-E_{W T}(t)\right] / \eta_{d} \\
E_{E S S}^{c}(t)=E_{E S S}(t-1)+\left[E_{P V}(t)+E_{W T}(t)-E_{\text {Load }}(t)\right] \cdot \eta_{c}
\end{gathered}
$$

where $E_{E S S}(t-1)$ is the energy at time $t-1$ in $(\mathrm{kWh}) ; E_{P V}, E_{W T}, E_{\text {Load }}$ are the PV energy, WT energy and load energies, respectively; $\eta_{d}$ and $\eta_{c}$ are the discharge and charge efficiencies of the ESS, respectively.

Equations (5) and (6) can be rewritten as (7) and (8) [10].

$$
\begin{aligned}
& E_{E S S}^{d}(t)=E_{E S S}(t-1)-P_{E S S}^{d}(t) \cdot \Delta t / \eta_{d} \\
& E_{E S S}^{c}(t)=E_{E S S}(t-1)+P_{E S S}^{c}(t) \cdot \Delta t \cdot \eta_{c}
\end{aligned}
$$

where $P_{E S S}^{d}(t)=P_{\text {Load }}(t)-P_{P V}(t)-P_{W T}(t)$ is the power discharged by the ESS; $P_{E S S}^{c}(t)=P_{P V}(t)+P_{W T}(t)-P_{\text {Load }}(t)$ is power charged into the ESS; and $\Delta t=1$ since the time interval is 1 hour.

\subsection{Load Profile}

The load profile determines the requirements of power supply from the hybrid MG power system. The load profile is modeled according to the dynamic load power demands $P_{\text {Load }}$ at times $t$. In off-grid power system design, the load profile is the driver. Figure 2 shows an example of a per-hour daily residential load demand profile for a group of some households. This double-bell curve, with high demands early in the morning and late in the evening, could be explained as follows:

- Most residents wake up in the morning to prepare for work and school (i.e. taking hot showers, preparing breakfast, etc.).

- People then leave for work and school typically from hours 7 to 18 on weekdays.

- Most household members are cooking/warming food, eating dinner, watching TV from hours 18 to 22 then go to bed.

The curve shown here in Figure 2 represents a weekend profile as people wake up later compared to week days and use more power during the day from staying at home. 


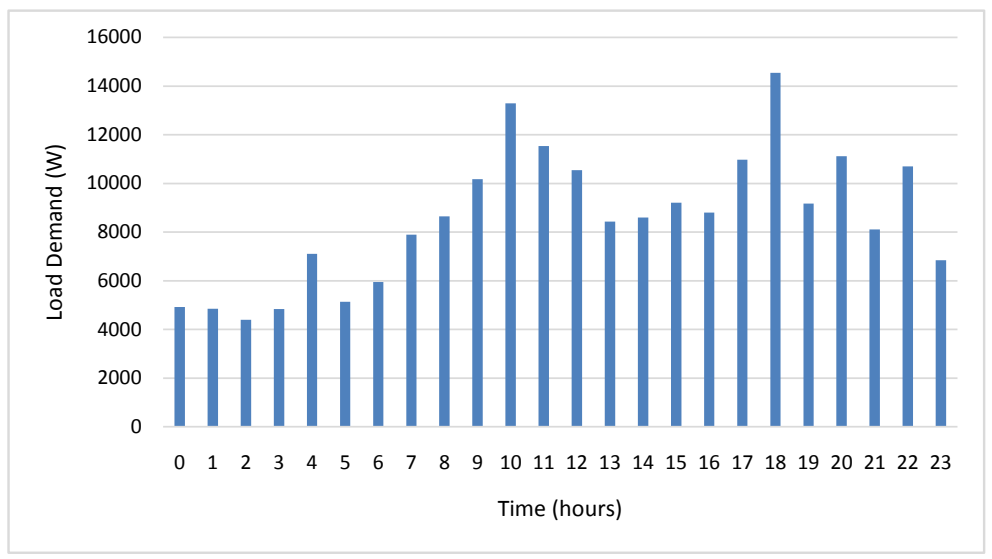

Figure 2. Daily residential load demand.

\subsection{Reliability Model}

The power balance of the system is illustrated in Figure 3. When the load demand exceeds the energy generated by PV and WT plus the energy stored in the ESS for hour $t$, this put the MG in a Loss of Power Supply scenario ( $\left.P_{\text {supplied }}(t)<P_{\text {needed }}(t)\right)$, which is expressed as

$$
\operatorname{LPS}(t)=P_{\text {Load }}(t)-\left[P_{P V}(t)+P_{W T}(t)+P_{E S S}^{d}(t)\right] \cdot \eta_{i n v} .
$$

where $\eta_{i n v}$ is the efficiency of the inverter.

The Loss of Power Supply Probability (LPSP), which is the reliability index of an MG system, for a given time period $T$ can be defined as the ratio of all $L P S(t)$ values for that period to the sum of the load demands [21].

$$
L P S P=\frac{\sum_{t=0}^{T} \operatorname{LPS}(t)}{\sum_{t=0}^{T} P_{\text {Load }}(t)}=\frac{\sum_{t=0}^{T} \text { Power failure time }}{T}
$$

\section{Problem Formulation}

\subsection{Objective Function}

The objective of this optimization problem is to minimize the capital and operating costs of the off-grid hybrid MG over a total life period of 20 years, while satisfying some reliability, operational and stability constraints. This optimization problem is expressed in (11) and (12) [12].

$$
\begin{gathered}
\min f\left(N_{P V}, N_{W T}, E_{E S S}\right)=C_{P V} \cdot N_{P V}+C_{W T} \cdot N_{W T}+C_{E S S} \cdot E_{E S S} \\
\left\{\begin{array}{l}
C_{P V}=\left(C_{c a p}^{P V}+20 \cdot C_{o p}^{P V}\right) \cdot P_{P V} \\
C_{W T}=\left(C_{c a p}^{W T}+20 \cdot C_{o p}^{W T}\right) \cdot P_{W T} \\
C_{E S S}=C_{c a p}^{E S S}+y_{E S S} \cdot C_{c a p}^{E S S}+\left(20-y_{E S S}-1\right) \cdot C_{o p}^{E S S}
\end{array}\right.
\end{gathered}
$$

where $N_{P V}$ is the number of PV panels; $N_{W T}$ is the number of wind turbines; $E_{E S S}$ is the storage capacity of the ESS in (Wh); $C_{P V}$ and $C_{W T}$ are the total costs in (US\$) of a PV and a WT, respectively; $C_{E S S}$ is the per-unit cost of the ESS in (US\$/Wh) of the ESS; $C_{c a p}^{P V}, C_{c a p}^{W T}$ and $C_{c a p}^{E S S}$ are the capitol costs of the 


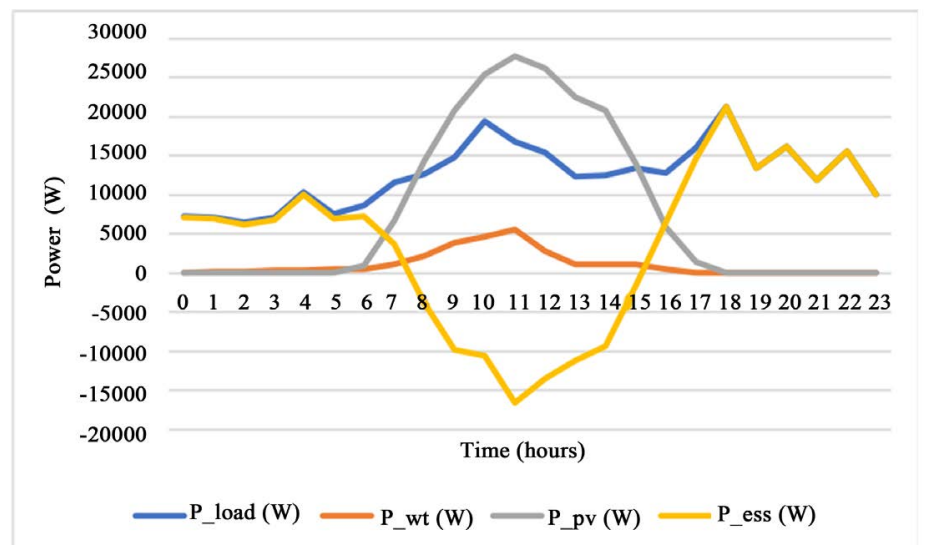

Figure 3. Power balance.

$\mathrm{PV}$ in (US\$/W), WT in (US\$/W) and ESS in (US\$/Wh), respectively; $C_{o p}^{P V}, C_{o p}^{W T}$ and $C_{o p}^{E S S}$ are the operating costs of the PVin (US\$/W), WT in (US\$/W) and ESS in (US\$/Wh), respectively; and $y_{E S S}$ is the expected number of ESS replacement over the 20 years. The capital cost of each component includes the purchase and installation cost of that component. The operation cost of each component includes the maintenance and operation cost of that component.

\subsection{Constraints}

The following constraints should be satisfied:

- Reliability:

$$
L P S P \leq L P S P_{\text {set }}
$$

- PV power limits:

$$
P_{P V \min } \leq P_{P V}(t) \leq P_{P V \max } ; N_{P V}=0,1,2, \cdots
$$

- WT power limits:

$$
P_{W T \min } \leq P_{W T}(t) \leq P_{W T \max } ; N_{W T}=0,1,2, \cdots
$$

- ESS stored energy and power limits:

$$
\begin{gathered}
E_{E S S \text { min }} \leq E_{E S S}(t) \leq E_{E S S \text { max }} \\
E_{E S S \text { min }}=(1-D O D) \cdot E_{E S S \text { max }} \\
0 \leq P_{E S S}^{d}(t) \leq P_{E S S \text { max }}^{d}=\min \left\{E_{E S S_{\max }} \cdot \eta_{d},\left(E_{E S S}(t-1)-E_{E S S \text { min }}\right) \cdot \eta_{d}\right\} \\
0 \leq P_{E S S}^{c}(t) \leq P_{E S S \text { max }}^{c}=\min \left\{E_{E S \text { max }} / \eta_{c},\left(E_{E S S \text { max }}-E_{E S S}(t-1)\right) / \eta_{c}\right\}
\end{gathered}
$$

In addition to the stored energy constraint, the charge and discharge powers of the ESS must be kept within a certain limit at any point of time. In Equations (18) and (19), the energy terms are divided by the time internal $\Delta t=1$ to get the powers.

- Energy balance (starting and ending limits):

$$
E_{E S S}(0)=E_{E S S}(T)=E_{\text {ESSstored }}
$$


- Power balance

$$
P_{P V}(t)+P_{W T}(t)+P_{E S S}(t)=P_{\text {Load }}(t)
$$

\section{Enhanced Genetic Algorithm}

In the past few decades, various nature-inspired computational methods have been developed to solve complex engineering problems [22] [23] [24] [25]. One such computational method is Evolutionary algorithms which are generic, optimization algorithms that are biology-inspired mechanisms. Geneticalgorithm (GA) is a rapidly growing area of Artificial Intelligence. It is an intelligent method for solving combinatorial, hard optimization problems in $\mathrm{n}$-dimensions. The flowchart of a GA is shown in Figure 4. The work in [18] proposed enhancements that give a new variant of the Standard GA. Five enhancements were

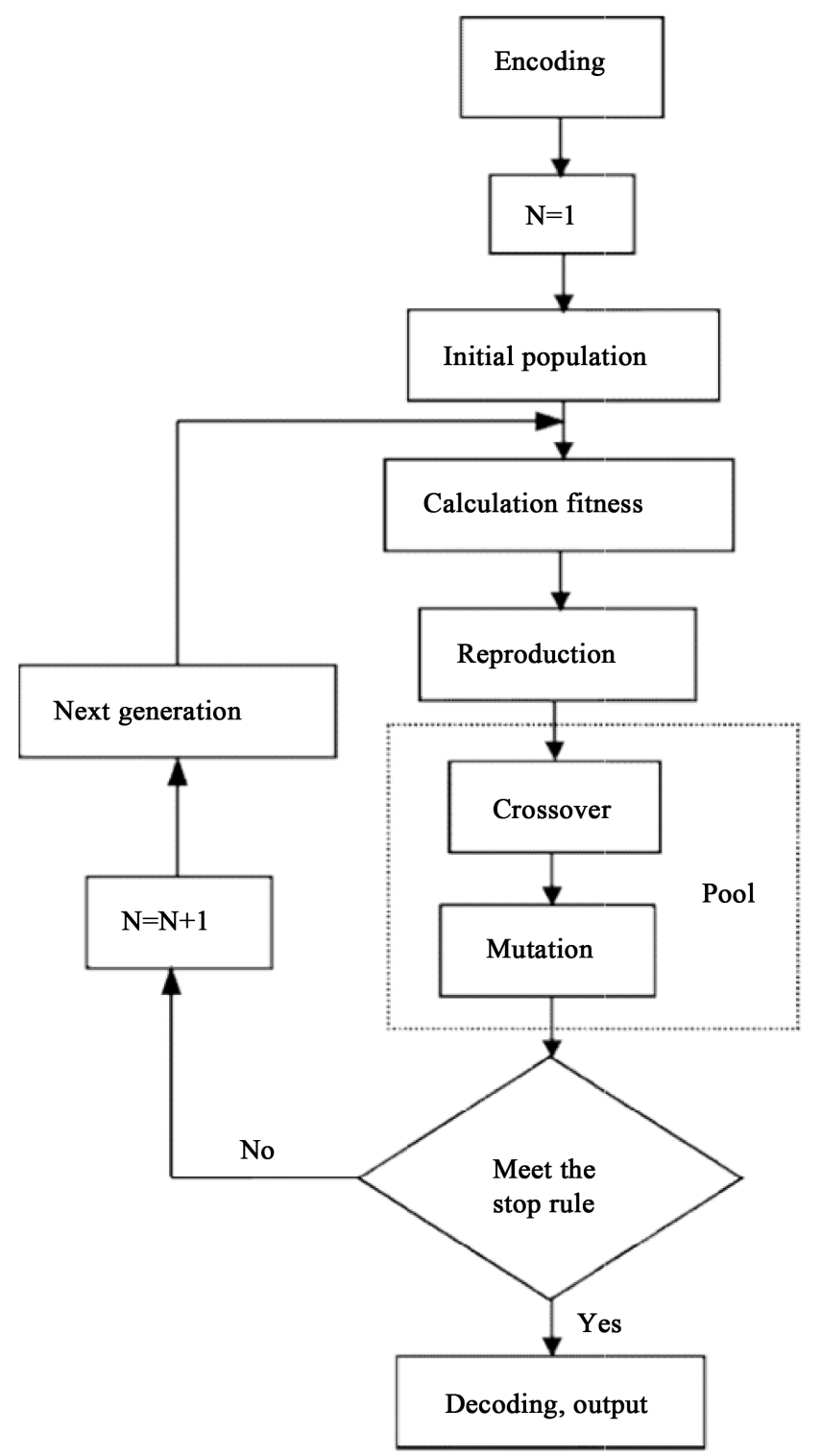

Figure 4. GA flowchart. 
were introduced (multiple weighted roulettes, multiple cross over points, multiple mates, utilizing the Daubechies wavelets (D4) and using normal distribution for selecting the initial population). The convergence velocity of the algorithm is also improved thereby reducing the time taken for the algorithm to reach the sought solution.

A basic part of the selection process is to stochastically select from one generation to another in order to create the basis of the next generation. The underlining requirement is that the set of fittest individuals would have a greater chance of survival than the set of weaker ones. This inheritance nature in those fitter individuals will tend to have a better probability of survival and will go on forward to form updated mating pool for the next generation. Weaker individuals are not left without a chance though. In nature those individuals may have genetic coding that may also prove useful to future generations.

Selection is the first genetic operation in the reproductive phase of GA. It helps the GA by directing the genetic search towards promising regions in the search space. Selection pressure is a crucial factor that determines the efficiency of the algorithm and is reduced in our proposed algorithm. The first enhancement proposed is to use multiple weighted roulettes, each designed to complement the others. This will further distribute the selection pressure for one generation to another. The job that GAs have in this case is to mate sets of individuals and then replicate this selection process. The usual implementation is by crossover. The only general requirement is that the offspring carry forward the important genetic material from the parents, whilst introducing enough variation that they survive. The crossover method emulates this process by exchanging chromosome patterns between individuals to create offspring for the next generation.

The second and third enhancements are to use multiple cross over points as well as using multiple mates as a function of results of mating individual parents creating some offspring. Those offspring will have of the genetic material of both parents. There are three options regarding the fitness of the offspring, they can be weaker, the same or fitter than their parents. If they are weaker they will tend to die out-if they are stronger their chances of survival are better. It is of general note that the stronger the parents are in terms of fitness then the fitter the offspring will be. The variation caused by this process allows the offspring to search out different available niches, i.e. find better fitness values and subsequently better solutions.

The fourth enhancement proposed is to utilize the Daubechies wavelet (D4), which is named after its discoverer the mathematician Ingrid Daubechies, as a preprocessing step. The D4 transform has four scaling function coefficients and can be extended to multiple levels as many times as the signal length can be divided by 2 . D4 was compared to other wavelets. The HAAR wavelet for instance is simple, memory efficient and computationally cheap. It uses two scaling and wavelet function coefficients, thus calculates pair wise averages and differences. 
Daubechies wavelet family is the most popular wavelet family used for texture feature analysis, due to orthogonal and compact support abilities. Daubechies averages over more pixels, it is smoother than the HAAR wavelet. It is Similar to the well-known Fourier transform, but it takes care of rapid transitions better than Fourier.

The fifth enhancement is used for initializing the initial population and it is done by replacing the uniform distribution with the normal distribution. The normal (Gaussian) distribution is the most widely known and used of all distributions. Because the normal distribution approximates many natural phenomena so well, it has developed into a standard of reference for many probability problems. That is why it was selected to be the fifth enhancement proposed to deal with the step of selecting the initial population. Some of the characteristics of the normal distribution are that it is symmetric, bell shaped and continuous for all values of $X$ between $-\infty$ and $\infty$ so that each conceivable interval of real numbers has a probability other than zero. Normal distribution is actually a family of distributions since the two parameters $\mu$ and $\sigma$ determine the shape of the distribution.

This enhanced GA was used in radar system application to detect the angle of arrival by analyzing readings from an array of multiple radars [26]. This paper will assess the robustness and accuracy of the developed enhanced GA in MG power system applications. The form of the individual of the GA's population is set to $\left[\mathrm{N}_{\mathrm{PV}} \mathrm{N}_{\mathrm{WT}} \mathrm{E}_{\mathrm{ESS}}\right]$. To accomplish this, a specific fitness function was developed along with a new data preprocessing program in Java to organize and prepare the data for importation into the enhanced GA search environment to evaluate every individual for 8760 hours per simulation cycle. A GA optimization can have many ways to use as a stop rule. The best one of course is if the optimum solution is known. However, since in this case the optimum solution was unknown, the system used the population size and a maximum number of generations as the stop rule.

\section{Case Study}

The location of Guzape (suburb of Abuja), Nigeria (Latitude $9^{\circ} 0^{\prime} 31^{\prime \prime N}$, Longitude $7^{\circ} 30^{\prime} 50^{\prime \prime} \mathrm{E}$ ) is used as site for the case study. The global horizontal solar irradiance Figure 5, ambient temperature Figure 6 and wind speed Figure 7 data were taken from the Typical Meteorological Year (TMY) data sets [27] and used to calculate the output powers of the PV and WT. Table 1 contains information about the PV, WT and ESS parameters used in this paper. The site consists of 10 apartments with some outside lighting. The estimated hourly load demand for the site is shown in Figure 8.

\section{Results and Discussion}

The enhanced GA was used to minimize the total MG cost, while considering different LPSP values for system reliability. The results were compared with 


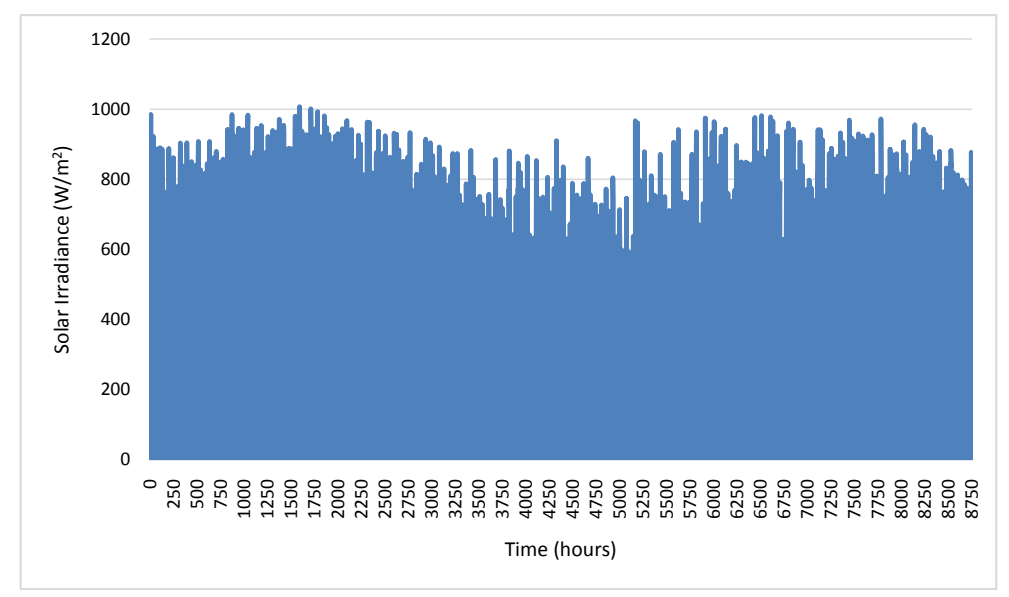

Figure 5. Hourly global solar irradiance of the year $\left(\mathrm{W} / \mathrm{m}^{2}\right)$.

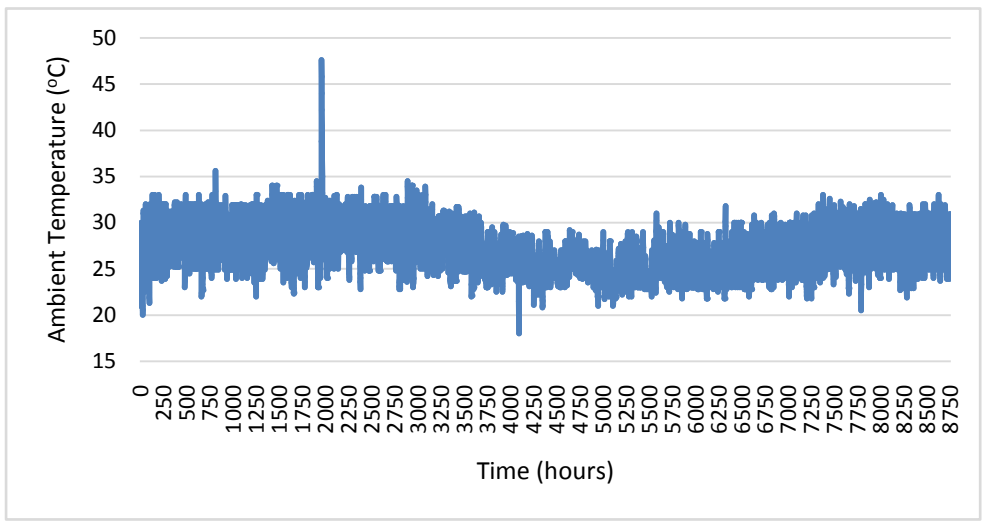

Figure 6. Hourly ambient temperature of the year $\left({ }^{\circ} \mathrm{C}\right)$.

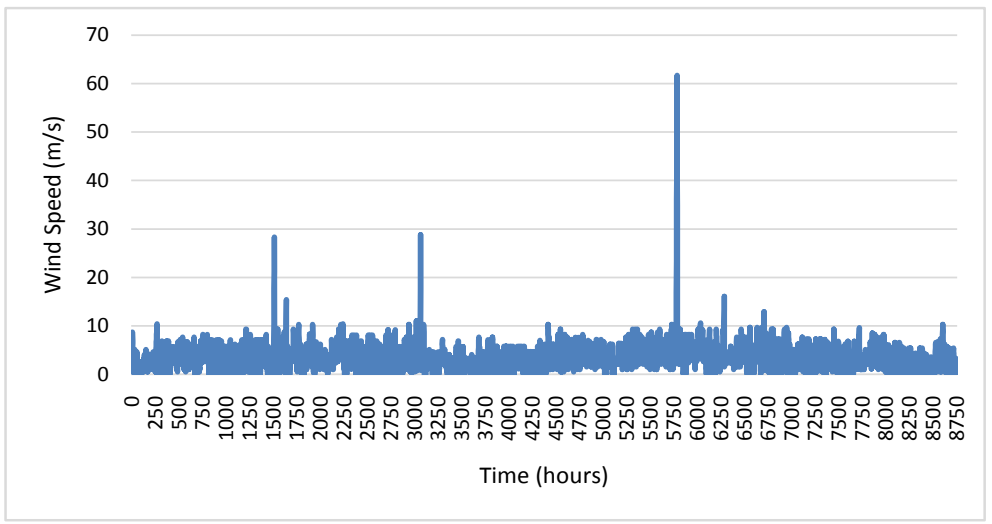

Figure 7. Hourly wind speed of the year $(\mathrm{m} / \mathrm{s})$.

those obtained from the Brute Force and standard GA. A comparison between the three strategies is presented in Table 2. The enhanced GA outperformed the standard GA in terms of speed as it took 41,218 less trials to reach the same result on the same machine. The results obtained from the enhanced GA agree with those from the two other methods. The effect of the ESS depth of discharge (DOD) on the MG system sizing and total coast is shown in Table 3. It was 


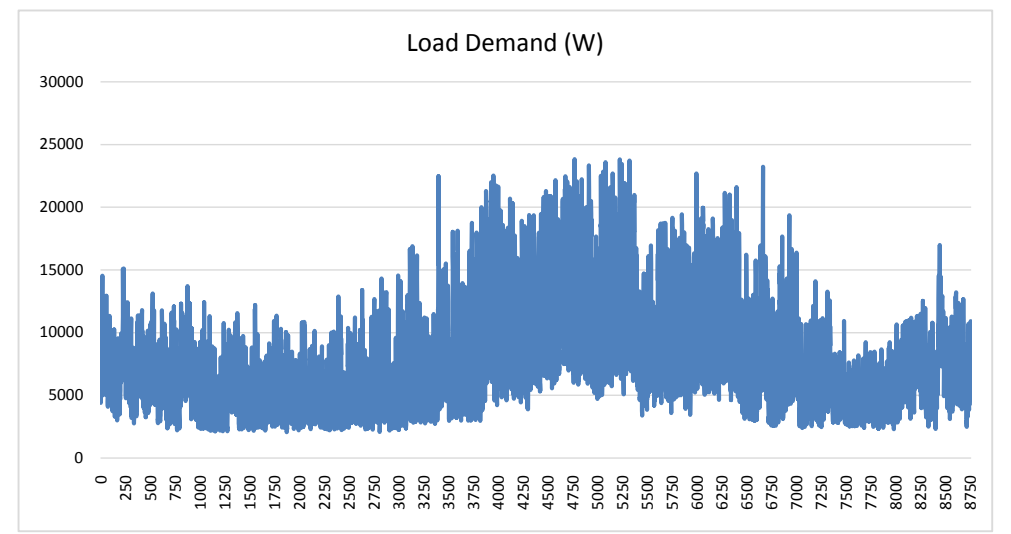

Figure 8. Hourly load demand for the year (W).

Table 1. Parameters of system components.

\begin{tabular}{|c|c|c|}
\hline & Parameter & Value \\
\hline \multirow{7}{*}{ PV Data } & Max power & $255 \mathrm{~W}$ \\
\hline & Efficiency at STC & $15.7 \%$ \\
\hline & Length & $1.64 \mathrm{~m}$ \\
\hline & Width & $0.99 \mathrm{~m}$ \\
\hline & Capital cost & $\$ 0.80 / \mathrm{W}$ \\
\hline & Operation cost & $\$ 0.04 / \mathrm{W}$ \\
\hline & Life time & $25 \mathrm{yr}$ \\
\hline \multirow{7}{*}{ WT Data } & Rated power & $1500 \mathrm{~W}$ \\
\hline & Cut-in wind speed & $2.5 \mathrm{~m} / \mathrm{s}$ \\
\hline & Cut-out wind speed & $17 \mathrm{~m} / \mathrm{s}$ \\
\hline & Rated wind speed & $12 \mathrm{~m} / \mathrm{s}$ \\
\hline & Capital cost & $\$ 0.67 / \mathrm{W}$ \\
\hline & Operation cost & $\$ 0.1005 / \mathrm{W}$ \\
\hline & Life time & $20 \mathrm{yr}$ \\
\hline \multirow{5}{*}{ ESS Data } & Charge efficiency & $80 \%$ \\
\hline & Discharge efficiency & $100 \%$ \\
\hline & Capital cost & $\$ 0.15 / \mathrm{Wh}$ \\
\hline & Operation cost & $\$ 0.015 / \mathrm{Wh}$ \\
\hline & Life time & $5 \mathrm{yr}$ \\
\hline
\end{tabular}

Table 2. Comparison of the three strategies.

\begin{tabular}{cccc}
\hline & Brute Force & Standard GA & Enhanced GA \\
\hline No. of Trials & $35,267,760$ & 117,624 & 76,406 \\
\hline
\end{tabular}

Table 3. Results of optimal sizing.

\begin{tabular}{ccccc}
\hline & DOD $=0.8$ & DOD $=0.7$ & DOD $=0.6$ & DOD $=0.5$ \\
\hline $\mathrm{N}_{\mathrm{PV}}$ & 164 & 166 & 168 & 176 \\
$\mathrm{~N}_{\mathrm{WT}}$ & 5 & 5 & 5 & 5 \\
$\mathrm{P}_{\mathrm{PV}}$ & $41.8 \mathrm{~kW}$ & $42.3 \mathrm{~kW}$ & $42.8 \mathrm{~kW}$ & $44.9 \mathrm{~kW}$ \\
$\mathrm{P}_{\mathrm{WT}}$ & $7.5 \mathrm{~kW}$ & $7.5 \mathrm{~kW}$ & $7.5 \mathrm{~kW}$ & $7.5 \mathrm{~kW}$ \\
$\mathrm{E}_{\mathrm{ESS}}$ & $200 \mathrm{kWh}$ & $200 \mathrm{kWh}$ & $200 \mathrm{kWh}$ & $200 \mathrm{kWh}$ \\
Total Cost & $\$ 25012.00$ & $\$ 255828.07$ & $\$ 256644.00$ & $\$ 259908.00$ \\
\hline
\end{tabular}




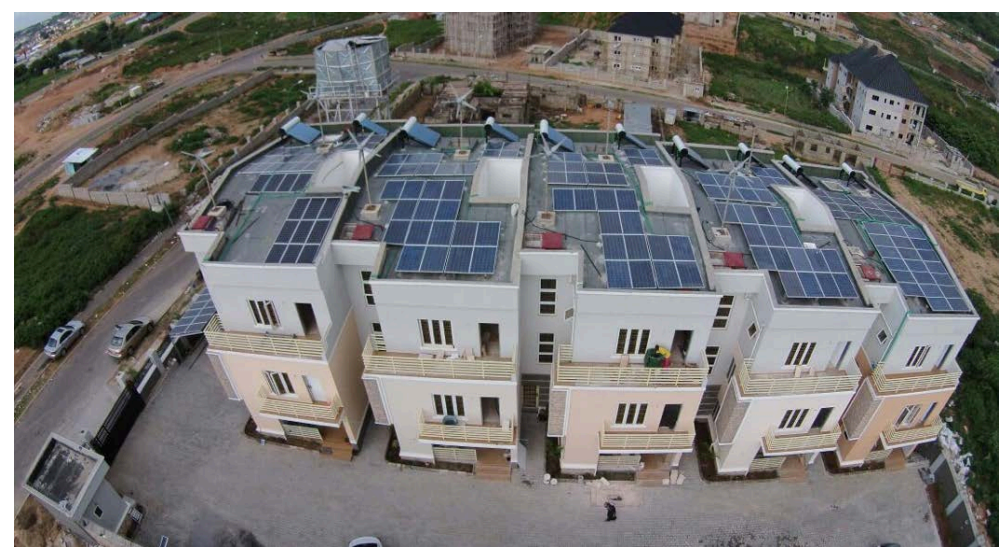

Figure 9. Aerial view of the site.

found that the optimal size of the site is 176 solar panels, 5 wind turbines with $200 \mathrm{kWh}$ of energy storage for the minimum total 20-year cost of $\$ 259,908.00$ based on the desired operation and reliability constraints with 50\% DOD and LPSP less than or equal to 0.15 . Figure 9 shows an aerial view of the project site in Nigeria.

\section{Conclusions}

An approach of sizing a PV/WT/ESS hybrid off-grid MG using an enhanced GA is proposed in this paper. A case study involving the optimal sizing of an off-grid MG system site in Nigeria using real field data was discussed. For the case study, a special Java program was developed along with the enhanced GA to obtain the optimal size of the MG.

That is the combination of PV, WT and ESS that met the load demand subject to the operation constraints and the desired LPSP with the minimum total MG cost over a period of 20 years. The result is compared to those obtained from the Brute Force and standard GA. All methods give the same result under the same conditions, showing that the enhanced GA is well suited for optimal MG system sizing, and the proposed method is feasible for sizing PV/WT/ESS hybrid off-grid MG systems.

\section{Acknowledgements}

This work was supported by the Information, Computation, Communication\& Control (ICCC) group at Oakland University, USA and Blue Camel Energy Ltd., a solar energy company based in Abuja, Nigeria. We thank Blue Camel Energy for providing site data and details that greatly contributed to the development of this manuscript. We thank Dr. Serge Kruk from the Department of Mathematics and Statistics at Oakland University for providing insight and expertise that greatly improved the manuscript.

\section{References}

[1] Carrasco, J., Franquelo, L., Bialasiewicz, J., Galvan, E., Guisado, R., Prats, R., Leon, 
J. and Moreno-Alfonso, N. (2006) Power Electronic Systems for the Grid Integration of Renewable Energy Sources: A Survey. IEEE Transactions on Power Electronics, 53, 1002-1016.

[2] Asmus, P. (2014) Why Microgrids Are Moving into the Mainstream: Improving the Efficiency of the Larger Power Grid. Electrification Magazine, IEEE, 2, 12-19. https://doi.org/10.1109/MELE.2013.2297021

[3] Shaahid, S.M. and Elhadidy, M.A. (2003) Opportunities for Utilization of Stand-Alone Hybrid (Photovoltaic + Diesel + Battery) Power Systems in Hot Climates. Renew Energy, 28, 1741-1753. https://doi.org/10.1016/S0960-1481(03)00013-2

[4] Li, J., Wei, W. and Xiang, J. (2012) A Simple Sizing Algorithm for Stand-Alone PV/Wind/Battery Hybrid Microgrids. Energies, 5, 5307-5323.

https://doi.org/10.3390/en5125307

[5] Traore, A., Taylor, A., Zohdy, M.A. and Peng, F.Z. (2017) Modeling and Simulation of a Hybrid Energy Storage System for Residential Grid-Tied Solar Microgrid Systems. Journal of Power and Energy Engineering, 5, 28-39.

https://doi.org/10.4236/jpee.2017.55003

[6] Yan, R., Saha, T.K., Modi, N., Masood, N-A. and Mosadeghy, M. (2015) The Combined Effects of High Penetration of Wind and PV on Power System Frequency Response. Applied Energy, 145, 320-330. https://doi.org/10.1016/j.apenergy.2015.02.044

[7] Balcombe, P., Rigby, D. and Azapagic, A. (2015) Environmental Impacts of Microgeneration: Integrating Solar PV, Stirling Engine CHP and Battery Storage. Applied Energy, 139, 245-259. https://doi.org/10.1016/j.apenergy.2014.11.034

[8] Amer, M., Namaane, A. and M'Sirdi, N.K. (2013) Optimization of Hybrid Renewable Energy Systems (HRES) Using PSO for Cost Reduction. Energy Procedia, 42, 318-327. https://doi.org/10.1016/j.egypro.2013.11.032

[9] Xu, D., Kang, L., Chang, L. and Cao, B. (2005) Optimal Sizing of Standalone Hybrid Wind/PV Power Systems using Genetic Algorithms. IEEE ECE Conference, Saskatoon, 1-4 May 2005, 1722-1725.

[10] Chen, S.X., Gooi, H.B. and Wang, M.Q. (2012) Sizing of Energy Storage for Microgrids. IEEE Transactions on Smart Grid, 3, 142-151. https://doi.org/10.1109/TSG.2011.2160745

[11] Yang, H., Lu, L. and Zhou, W. (2007) A Novel Optimization Model for Hybrid Solar-Wind Power Generation System. Solar Energy, 81, 76-84.

https://doi.org/10.1016/j.solener.2006.06.010

[12] Tito, M.S.R., Lie, T.T. and Anderson, T. (2013) A Simple Sizing Optimization Method for Wind-Photovoltaic-Battery Hybrid Renewable Energy Systems. Proceedings of the 20 th Electronics New Zealand Conference, 5, 8-12.

[13] Xiao, H., Pei, W., Yang, Y. and Kong, L. (2014) Sizing of Battery Energy Storage for Micro-Grid Considering Optimal Operation Management. International Conference on Power System Technology, No. CP1697, 3162-3169. https://doi.org/10.1109/POWERCON.2014.6993661

[14] Fossati, J.P., Galarza, A., Martín-Villate, A. and Fontan, L. (2015) A Method for Optimal Sizing Energy Storage Systems for Microgrids. Renewable Energy, 77, 539-549. https://doi.org/10.1016/j.renene.2014.12.039

[15] Arefifar, S.A., Paz, F. and Ordonez, M. (2017) Improving Solar Power PV Plants Using Multivariable Design Optimization. IEEE Journal of Emerging and Selected 
Topics in Power Electronics, 5, 638-650. https://doi.org/10.1109/JESTPE.2017.2670500

[16] Zhao, B., et al. (2013) Optimal Sizing, Operating Strategy and Operational Experience of a Stand-Alone Microgrid on Dongfushan Island. Applied Energy, 113, 1656-1666. https://doi.org/10.1016/j.apenergy.2013.09.015

[17] Mahesh, A. and Sandhu, K.S. (2017) A Genetic Algorithm Based Improved Optimal Sizing Strategy for Solar-Wind-Battery Hybrid System Using Energy Filter Algorithm. Frontiers in Energy, 1-13. https://doi.org/10.1007/s11708-017-0484-4

[18] Elgothamy, H., Zohdy, M.A. and Abdel-Aty-Zohdy, H.S. (2014) Design and Application of an Enhanced GA. IEEE 57 th International Midwest Symposium on Circuits and Systems, College Station, 3-6 August 2014, 864-867. https://doi.org/10.1109/MWSCAS.2014.6908552

[19] Patel, M.R. (1999) Wind and Solar Power System. CRC Press, Boca Raton.

[20] Lan, H., Wen, S., Hong, Y., Yu, D.C. and Zhang, L. (2015) Optimal Sizing of Hybrid PV/Diesel/Battery in Ship Power System. Applied Energy, 158, 26-34. https://doi.org/10.1016/j.apenergy.2015.08.031

[21] Yang, H., et al. (2008) Optimal Sizing Method for Stand-Alone Hybrid Solar-Wind System with LPSP Technology by Using Genetic Algorithm. Solar Energy, 82, 354-367. https://doi.org/10.1016/j.solener.2007.08.005

[22] Garbacik, N.R. and Zohdy, M.A. (2008) Genetic Algorithm: Scattered Data Problems Using Lipschitz Interpolation. Aerospace and Electronics Conference, Dayton, 16-18 July 2008, 56-58. https://doi.org/10.1109/NAECON.2008.4806516

[23] Khan, A.A. and Zohdy, M.A. (1997) A Genetic Algorithm for Selection of Noisy Sensor Data in Multisensor Data Fusion. American Control Conference, Albuquerque, June 1997, 2256-2262.

[24] Zohdy, M.A., Loh, K., Liu, N., Jun, A. and Abdul-Wahab, A. (1989) Application of Maximum Likelihood Identification with Multisensor Fusion to Time-Varying Stochastic System. Journal of Chemical Neuroanatomy.

[25] Alfaro, A., Doan, M., Finke, J., Galdes, M. and Zohdy, M.A. (2007) Application of Divide and Conquer Extended Genetic Algorithm to Tertiary Protein Structure of Chymotrypsin Inhibitor-2. Applied Bionics and Biomechanics, 3, 263-271.

[26] Elgothamy, H., Zohdy, M.A. and Abdel-Aty-Zohdy, H.S. (2018) Application of an Enhanced Genetic Algorithm to Radar System. International Journal of Advanced Research in Computer and Communication Engineering, 7, 37-43.

[27] National Renewable Energy Laboratory (NREL). PVWatts. http://pvwatts.nrel.gov 